\title{
Reactivity of Anti-Nipah Virus Monoclonal Antibodies to Formalin-fixed, Paraffin- embedded Lung Tissues from Experimental Nipah and Hendra Virus Infections
}

\author{
Nobuhiko TANIMURA ${ }^{1)}$, Tadao IMADA ${ }^{1)}$, Yoshihito KASHIWAZAKI ${ }^{2)}$, Shahirudin SHAMUSUDIN ${ }^{2)}$, \\ Sharifah SYED HASSAN ${ }^{2)}$, Aziz JAMALUDDIN ${ }^{2)}$, Gail RUSSELL ${ }^{3)}$ and John WHITE ${ }^{3)}$ \\ ${ }^{1)}$ National Institute of Animal Health, 3-1-5 Kannondai, Tsukuba, Ibaraki 305-0856, Japan, ${ }^{2)}$ Veterinary Research Institute, Department \\ of Veterinary Services, 59, Jalan Sultan Azlan Shah, 31400 Ipoh, Perak Darul Ridzuan, Malaysia and ${ }^{3)}$ CSIRO, Livestock Industries, \\ Australian Animal Health Laboratory, Private Bag 24, Geelong, Victoria, 3220, Australia
}

(Received 13 February 2004/Accepted 12 May 2004)

ABSTRACT. The immunohistochemical reactivity of seven clones of mouse monoclonal antibodies raised to Nipah virus antigens were investigated using formalin-fixed, paraffin embedded porcine and equine lung tissues from experimental Nipah and Hendra virus infection, respectively. Either microwave irradiation or enzymatic digestion effectively unmasked the viral antigens in formalin-fix ed, paraffin-embedded tissue sections. Four clones showed positive reaction to both Nipah virus-infected porcine lung tissue and Hendra virusinfected equine lung tissue. Two clones (11F6 and 13A5) reacted with Nipah virus-infected porcine lung tissue, but not with Hendra virus-infected equine lung tissue. These Nipah virus-specific monoclonal antibodies may therefore be useful for immunohistological diagnosis of Nipah virus infection and for further research on Nipah virus pathogenesis.

KEY WORDS: immunohistochemistry, monoclonal antibody, Nipah virus.

Nipah virus is a new paramyxovirus which emerged in Malaysia from 1998 to 1999 and caused fatal encephalitis in humans [1] and respiratory and neurological syndrome in pigs $[13,15]$. Hendra virus is also a lethal zoonotic paramyxovirus which caused respiratory disease in humans and horses in Australia [11]. Nipah virus and Hendra virus contain cross-reactive antigenic domains that are not shared with any other members of the Paramyxoviridae. Phylogenetic analysis demonstrated that although Nipah virus and Hendra virus are closely related, they are distinct from any of the established genera within the Paramyxoviridae [3].

Immunohistochemistry is highly recommended for laboratory diagnostic tests of Nipah virus infection, because it is performed on formalin-fixed tissues in which the virus is inactivated [2]. The tissue tropism of Nipah virus in humans and pigs has been examined by polyclonal anti-Nipah virus antibody $[5,10,16]$ and anti-Hendra virus antibody $[1,5$, 10, 16]. Both Nipah and Hendra viruses induced syncytial cells in vascular tissues and they were primarily vasotropic and/or neurotropic, generating interstitial pneumonia or encephalitis $[1,4,5,11,16]$. Nipah virus in pigs was also epitheliotropic in respiratory epithelium $[5,10]$. However, immunohistochemical detection of Nipah virus antigens on formalin-fixed, paraffin-embedded tissues using monoclonal antibodies has not been reported. Monoclonal antibodies against formalin-inactivated Nipah virus isolated from the lung of a field pig have recently been characterized [7]. The purpose of the present study is to examine the immunohistochemical reactivity of these monoclonal antibodies to Nipah and Hendra virus antigens in formalinfixed, paraffin-embedded porcine and equine lung tissues, respectively, and to establish a monoclonal antibody-based immunohistochemical detection method specific to Nipah virus antigens.
Seven monoclonal antibodies [7] were used as primary antibodies to Nipah virus antigens. Paraffin blocks of Nipah virus-infected porcine lung tissue and Hendra virus-infected equine lung tissue were provided by the Australian Animal Health Laboratory (CSIRO, Australia). Accommodation of virus-infected animals and necropsy were carried out at Biosafety Level 4. Two 6-week-old pigs were inoculated with 50,000 median tissue culture infective dose $\left(\right.$ TCID $\left._{50}\right)$ Nipah virus subcutaneously [10]. Seven and 8 days after inoculation, each pig was killed by intravenous inoculation of pentobarbital sodium and the lung tissues were fixed with $10 \%$ neutral buffered formalin and embedded in paraffin. A 7year-old horse was inoculated with 50,000 TCID $_{50}$ Hendra virus [4] subcutaneously. Necropsy was conducted after 7 days post-inoculation and the lung tissue was fixed with $10 \%$ neutral buffered formalin and embedded in paraffin.

For immunohistochemical staining, $4 \mu \mathrm{m}$ sections mounted on silane-coated glass slides were deparaffinized in xylene and alcohol. Endogenous peroxidase activity in sections was blocked by $3 \% \mathrm{H}_{2} \mathrm{O}_{2}$ in PBS for $15 \mathrm{~min}$. For antigen retrieval, sections were digested by $1 \mathrm{mg} / \mathrm{ml}$ of actinase E (Kaken Seiyaku Inc., Tokyo, Japan) in PBS for 5 to $20 \mathrm{~min}$ at $37^{\circ} \mathrm{C}$, or heated by microwave [9] at maximum output (approximately 500W) in citrate buffer ( $\mathrm{pH} 6.0$ ) (DAKO ChemMate $^{\mathrm{TM}}$, Buffer for Antigen Retrieval, DakoCytomation, Denmark) in four cycles of $5 \mathrm{~min}$ each. Primary antibodies were applied for $30 \mathrm{~min}$ at room temperature. Optimal dilution of primary antibody (12A5, 18C4) and optimal antigen retrieval method were previously determined by titration experiments. Hybridoma culture supernatants of 11F6, 12D7, 13A5 and 13C4 were directly applied to sections. This step was followed by sequential application of goat anti-mouse IgG antibody conjugated with peroxidase (Histofine, Simple stain, Nichirei Inc., 
Tokyo, Japan), and diaminobenzidine chromogen (Histofine, Simple stain, Nichirei Inc., Tokyo, Japan) according to the manufacturer's protocol. Sections were then counterstained in hematoxylin. The specificity of the staining procedures were ascertained by the introduction of negative controls consisting of experimentally Aujeszky's disease virus (ADV) -infected [12] and porcine reproductive and respiratory syndrome virus (PRRSV) -infected [8] porcine tissue samples. In addition, the primary antibodies raised to Nipah virus were substituted with the irrelevant monoclonal anti-canine distemper virus nucleoprotein antibody (VMRD, Inc., Pullman, WA) or anti-respiratory syncytial virus antibody (18B2) ( ARGENE Inc., Massapequa, NY).

Six of seven monoclonal antibodies yielded intense positive staining in the Nipah virus-infected porcine lung tissues (Table 1). The positively stained cells included bronchial (Fig. 1A), bronchiolar, alveolar epithelial cells (Fig. 1B), vascular endothelial and smooth muscle cells (Fig. 1C). Immunohistochemical staining by use of serial sections confirmed that all six monoclonal antibodies reacted with the same cells. Although 11E11 has strong neutralizing activity [7], no positive staining was obtained with 11E11 using any antigen retrieval method or concentration of immunoglobulin. 11E11 may recognize an epitope within the protein molecule that is modified irreversibly by formalin fixation [14] and paraffin embedding. 12A5 reacted intensely without use of the antigen retrieval method. An antigenic structure recognized by $12 \mathrm{~A} 5$ might be formalin-resistant and not modified after fixation [14]. No relationship was found between the optimal antigen retrieval method and the Nipah virus protein presumed to be recognized by each monoclonal antibody [7].

$12 \mathrm{~A} 5,12 \mathrm{D} 7,13 \mathrm{C} 4$, and $18 \mathrm{C} 4$ had cross-reaction with Hendra virus antigens in an equine lung tissue (Table 1). Endothelial and smooth muscle cells of pulmonary artery and endothelial cells of alveolar capillaries were stained positively in the equine lung tissue. However, 11E11, 11F6 and 13A5 did not show any cross-reaction with Hendra virus antigens (Table 1). The immunohistochemical crossreactivity on formalin-fixed, paraffin embedded tissues was consistent with the cross-reactivity of these antibodies in the indirect florescence antibody test on Nipah and Hendra virus-infected cells [7].

The previous electron microscopic observation of the Nipah virus-infected porcine lungs revealed that viral nucleocapsids were present within respiratory epithelia, such as alveolar, bronchiolar, and tracheal epithelial cells, but not in the vascular endothelia [6]. Nipah virus budding from bronchiolar epithelial cells within an experimentally infected pig was also demonstrated [10]. The distribution of Nipah virus antigens in the porcine lungs was consistent with that in the previous report using polyclonal anti-Nipah virus antibody and experimentally Nipah virus-infected pigs [10]. These results suggest that the monoclonal antibodies raised against Nipah virus identify the cells in which Nipah virus replicates. Further ultrastructural study may be necessary to examine the presence of viruses or nucleocapsids within vascular endothelia and smooth muscles and the pathogenesis of vasculitis [10].

The ultrastructural examination of Hendra virus-infected equine lungs showed that the Hendra virus replicates in syncytial cells of the vascular endothelia [6]. The distribution of Hendra virus antigens in the equine lung was consistent with that in the previous report using polyclonal anti-Hendra virus antibody and experimentally Hendra virus-infected horses [4]. The present results suggest that the monoclonal antibodies (12A5, 12D7, 13C4, 18C4) raised against Nipah virus cross-react with the viral antigens in the cells in which Hendra virus replicates.

All seven clones of monoclonal antibodies raised against Nipah virus did not react with ADV antigens or PRRSV

Table 1. Immunohistochemical reactivity of anti-Nipah virus antibodies to Nipah virus and Hendra virus antigens in formalin-fixed, paraffin-embedded lung tissues

\begin{tabular}{|c|c|c|c|c|}
\hline \multirow{2}{*}{$\begin{array}{l}\text { Clone } \\
\text { name }{ }^{a)}\end{array}$} & \multirow{2}{*}{$\begin{array}{l}\text { Concentration of } \\
\text { immunoglobulin }^{\text {) }}\end{array}$} & \multirow{2}{*}{$\begin{array}{l}\text { Optimal antigen } \\
\text { retrieval method }{ }^{\mathrm{c})}\end{array}$} & \multicolumn{2}{|c|}{ Immunohistochemical staining $^{\mathrm{d}}$} \\
\hline & & & Nipah virus & Hendra virus \\
\hline $11 \mathrm{E} 11$ & $3.5 \mu \mathrm{g} / \mathrm{m} l$ & No effect & - & - \\
\hline 11F6 & Supernatant & Microwave & ++ & - \\
\hline $13 \mathrm{~A} 5$ & Supernatant & Microwave & ++ & - \\
\hline $18 \mathrm{C} 4$ & $0.8 \mu \mathrm{g} / \mathrm{m} l$ & Actinase E (20 min) & ++ & \pm \\
\hline $13 \mathrm{C} 4$ & Supernatant & Microwave & ++ & + \\
\hline $12 \mathrm{~A} 5$ & $0.2 \mu \mathrm{g} / \mathrm{m} l$ & unnecessary & ++ & ++ \\
\hline $12 \mathrm{D} 7$ & Supernatant & Actinase E (5 min) & ++ & ++ \\
\hline
\end{tabular}

a) Clone names of monoclonal antibodies [7].

b) Purified immunoglobulins of 11E11, 12A5, and 18C4, and supernatant fluids of other monoclonal antibodies were applied to tissue sections.

c) Microwave $=$ Tissue sections were heated in Citrate buffer (pH6.0) by microwave in four cycles of 5 min each. Actinase $\mathrm{E}=$ Tissue sections were digested in $\mathrm{PBS}$ containing $0.1 \%$ actinase $\mathrm{E}$ at $37^{\circ} \mathrm{C}$ for 5 or $20 \mathrm{~min}$.

d) Lung tissues of pigs experimentally infected with Nipah virus and lung tissues of a horse experimentally infected with Hendra virus were used for immunohistochemical examination.

$++=$ intense (dark brown) staining, $+=$ weak (light brown) staining, $\pm=$ minimally detectable staining, $-=$ no staining. 

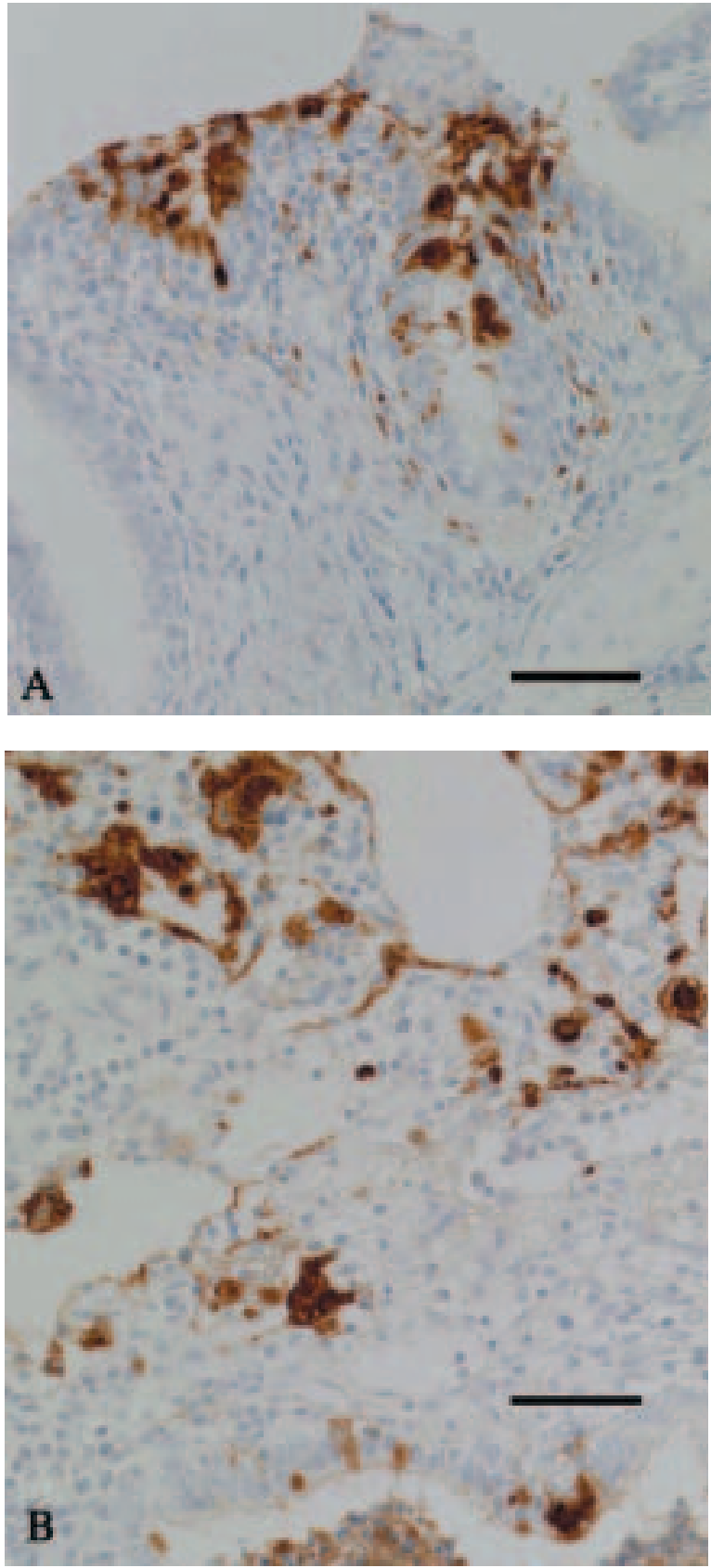

antigens in the lung tissues of pigs experimentally infected with ADV or PRRSV, respectively. Monoclonal antibodies against canine distemper virus nucleoprotein and respiratory syncytial virus did not react with the Nipah virus antigens in the experimentally Nipah virus-infected porcine lung tissues or Hendra virus antigens in the experimentally Hendra virus-infected equine lung tissue. These results support the validity of immunohistochemical procedures used in this study.

In conclusion, the present study demonstrated that the anti-Nipah virus monoclonal antibodies 11F6 and 13A5 can

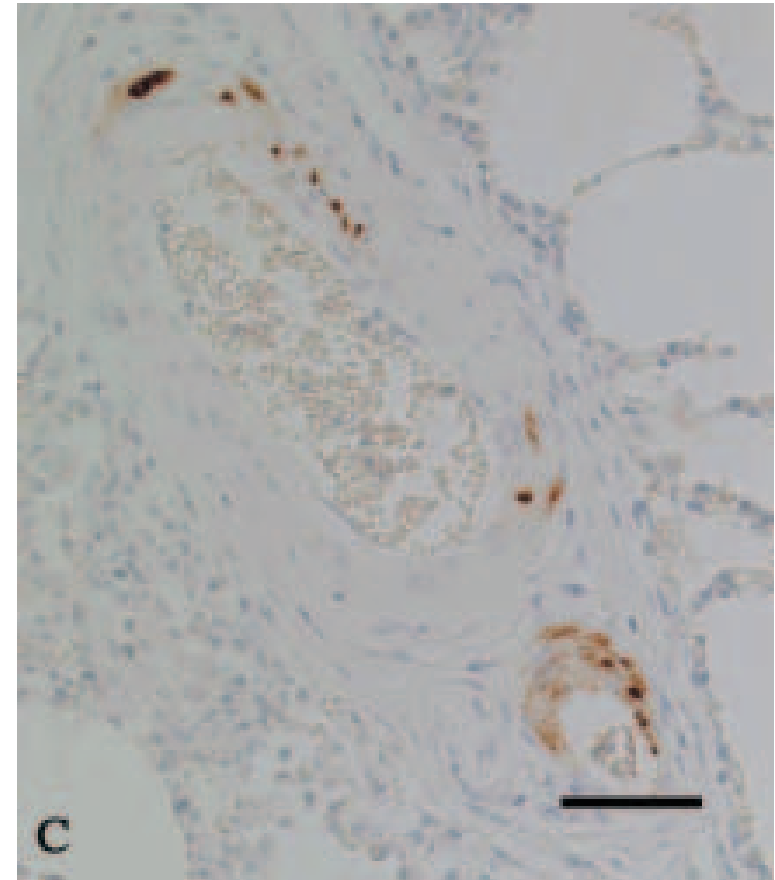

Fig. 1. Lung of a pig inoculated with Nipah virus (7 days postinoculation). Indirect immunoperoxidase method using monoclonal anti-Nipah virus antibody 11F6 and diaminobenzidine chromogen. Hematoxylin counterstain. Bar $=50 \mu \mathrm{m}$. A) Bronchial epithelial cells, desquamated or exudative cells, and interstitial cells show positive reaction. B) Bronchiolar epithelial cells, alveolar epithelial cells and exudative cells show positive reaction. C) Endothelial cells and smooth muscle cells of small arteries show positive reaction.

specifically detect Nipah virus antigens in formalin-fixed, paraffin-embedded lung tissues from experimentally-inoculated pigs. These Nipah virus-specific monoclonal antibodies may therefore be useful for immunohistochemical differential diagnosis of Nipah and Hendra virus infection and for further research on Nipah virus pathogenesis.

This study was supported by the joint study project of Japan International Cooperation Agency and Veterinary Research Institute, Malaysian Ministry of Agriculture, on the epidemiology, pathogenesis and molecular characterization of Nipah virus. 


\section{REFERENCES}

1. Chua, K.B., Bellini, W.J., Rota, P.A., Harcourt, B.H., Tamin, A., Lam, S.K., Ksiazek, T.G., Rollin, P.E., Zaki, S.R., Shieh, W.-J., Goldsmith, C.S., Gubler, D.J., Roehrig, J.T., Eaton, B., Gould, A.R., Olson, J., Field, H., Daniels, P., Ling, A.E., Peters, C.J., Anderson, L.J. and Mahy, B.W.J. 2000. Science 288: $1432-1435$.

2. Daniels, P.W., Lee, O.B. and Aziz, J. 2002. pp. 111-116. In: Trends in Emerging Viral Infections of Swine, 1st ed. (Morilla, A., Yoon, K.-J. and Zimmerman, J.J. eds.), Iowa State Press, Ames, IA.

3. Harcourt, B.H., Tamin, A., Ksiazek, T.G., Rollin, P.E., Anderson, L.J., Bellini, W.J. and Rota, P.A. 2000. Virology 271: 334-349.

4. Hooper, P.T., Ketterer, P.J., Hyatt, A.D. and Russell, G.M. 1997. Vet. Pathol. 34: 312-322.

5. Hooper, P., Zaki, S., Daniels, P. and Middleton, D. 2001. Microbes Infect. 3: 315-322.

6. Hyatt, A.D., Zaki, S.R., Goldsmith, C.S., Wise, T.G. and Hengstberger, S.G. 2001. Microbes Infect. 3: 297-306.

7. Imada, T., Mohd, A.A.R., Kashiwazaki, Y., Tanimura, N., Sharifah, S.H. and Aziz, J. 2004. J. Vet. Med. Sci. 66: 81-83.

8. Kawashima, K., Narita, M. and Yamada, S. 1999. Vet. Immu- nol. Immunopathol. 71: 257-262.

9. Leong, A.S.-Y. and Leong, F.J.W.-M. 2002. Acta Histochem. Cytochem. 35: 367-374.

10. Middleton, D.J., Westbury, H.A., Morrissy, C.J., van der Heide, B.M., Russell, G.M., Braun, M.A. and Hyatt, A.D. 2002. J. Comp. Pathol. 126: 124-136.

11. Murray, K., Selleck, P., Hooper, P., Hyatt, A., Gould, A., Gleeson, L., Westbury, H., Hiley, L., Selvey, L., Rodwell, B. and Ketterer, P. 1995. Science 268: 94-97.

12. Narita, M., Kawashima, K., Nakagawa, H., Uchimura, A., Ohashi, T., Kimura, K. and Tanimura, N. 1997. J. Comp. Pathol. 117: 25-33.

13. Nor, M.N.M., Gan, C.H. and Ong, B.L. 2000. Rev. Sci. Tech. Off. Int. Epiz. 19: 160-165.

14. Shi, S.-R., Cote, R.J. and Taylor, C.R. 1997. J. Histochem. Cytochem. 45:327-343.

15. Singh, J. and Aziz, J. 2002. pp. 105-110. In: Trends in Emerging Viral Infections of Swine, 1st ed. (Morilla, A., Yoon, K.-J. and Zimmerman, J.J. ed.), Iowa State Press, Ames, IA.

16. Wong, K.T., Shieh, W.-J., Kumar, S., Norain, K., Abdullah, W., Guarner, J., Goldsmith, C.S., Chua, K.B., Lam, S.K., Tan, C.T., Goh, K.J., Chong, H.T., Jusoh, R., Rollin, P.E., Ksiazek, T.G., Zaki, S.R. and the Nipah virus pathology working group. 2002. Am. J. Pathol. 161: 2153-2167. 